Int. J. Morphol.,

33(3):908-913, 2015.

\title{
Fractal Analysis of Skeletal Muscle Tissue of Rats Subjected to Stretch Injury
}

\author{
Análisis Fractal de Tejido Muscular Esquelético en Ratas Sometidas a Lesión por Estiramiento
}

\author{
Guilherme Ozaki"; Regina Celi Trindade Camargo*; Tatiana Emy Koike*; \\ Thiago Alves Garcia*; Robson Chacon Castoldi* \& Jose Carlos Silva Camargo Filho*
}

OZAKI, G.; CAMARGO, R. C. T.; KOIKE, T. E.; GARCIA, T. A.; CASTOLDI, R. C. \& CAMARGO FILHO, J. C. S. Fractal analysis of skeletal muscle tissue of rats subjected to stretch injury. Int. J. Morphol., 33(3):908-913, 2015.

SUMMARY: The aim of this study was to analyze changes in the skeletal muscle tissue of rats after muscle stretch injury using fractal analysis. Nineteen rats were divided into three groups, Control $(n=5)(C)$, Lesion two days $(n=7)(L 2)$, and Lesion seven days $(n=$ 7) (L7). Histological slides of the gastrocnemius muscle of the animals were prepared and stained with Hematoxylin and eosin for analysis of the inflammatory process, and picrosirius for the demonstration of collagen. The stained slides were subsequently analyzed using Fractal Dimension (FD). The results showed high FD values of the inflammatory process in the experimental groups L2 and L7 in relation to $\mathrm{C}(\mathrm{p}=0.000)$. The analysis of collagen in the picrosirius stained slides showed high FD in the L2 group compared to the L7 ( $\mathrm{p}=$ 0.0001), with no statistically significant difference among other groups. In summary, the present study demonstrated that fractal analysis was able to identify changes in the inflammatory process in injured skeletal muscle tissue.

KEY WORDS: Fractal analysis; Skeletal muscle injury; Collagen; Inflammation; Pathology.

\section{INTRODUCTION}

Muscle injury promotes a series of changes in skeletal muscle tissue. Such alterations are visible when analyzed using histological slides in a light microscope (Alves et al., 2013; Camargo Filho et al., 2011; Luo et al., 2013; de Souza et al., 2011). However, currently these microscopic changes are evaluated qualitatively, which does not enable quantification of morphological changes. To this end, fractal analysis has been studied as it presents itself as a tool that enables the quantification of histological findings, in addition to eliminating variations between raters (Lee et al., 2014; Moreira et al., 2011).

A fractal is an object that has no classical geometrical form; each small part of it resembles the whole. An example of a fractal object that illustrates this concept is the "Koch snowflake" (Fig. 1). The Koch snowflake is a complex figure; it is not possible to map all its points, because every time you improve the resolution, new anfractuosities appear where before there was apparently only one line segment (Mendonca et al., 2007).

Thus the analysis of fractal objects is based on the ratio between the resolution and the range in which the object is evaluated, and the results can be expressed quantitatively as the fractal dimension (FD) of the object, expressed by the equation:

$$
\mathrm{FD}=(\log \mathrm{Nr} / \log \mathrm{r}-1)
$$

Where $\mathrm{Nr}$ is the number of elements necessary to overlap or fill the original object, in which $r$ the rule or scale applied to the object and FD is the dimension of the structure or object.

The are several techniques to determine FD, among which the most widely used in the medical field is the boxcounting method (Moreira et al.). In this method the FD is given by the overlapping of the square (n) of the sides (r), progressively smaller, so $\mathrm{Nr}$ is the number of squares of $\mathrm{r}$ sides, of each chosen size, necessary to cover the image. In this case FD is the slope of the regression line of the values of the two logs (Karperien et al., 2008).

FD is already used as a diagnostic tool in many fields of research, including studies of; neurons (Ristanovic' et al., 2014); retinal vasculature (Mendonca et al.); bronchial 
tree (Gupta et al., 2014); tissue blood perfusion (Michallek \& Dewey 2014); diagnosis of hepatocellular carcinoma (Lee et al.); degree of differentiation of osteoblasts (Park et al., 2014) and degree of myocardial cellular rejection after heart transplantation (Moreira et al.), among others. However; despite being a technique with good applicability for histological analysis, no research was found in the scientific literature assessing injured skeletal muscle tissue using fractal dimension. The use of this technique could open the way for a standardized measurement of histological findings, allowing more precise analysis of results, and enabling direct comparison of results between studies, as it is a technique in which the results are independent of the evaluator.

Therefore the present study aimed to analyze the changes in the skeletal muscle tissue of rats after stretch injury, using the fractal dimension.

\section{MATERIAL AND METHOD}

Nineteen male Wistar (Rattus novergicus) rats (aged 150 days) were used, acquired from the central Bioterium of Paulista State University (UNESP), Botucatu- SP Campus (Brazil). They were maintained at the bioterium of the Histology and Histochemistry Laboratory at the Faculty of Science and Technology, Presidente Prudente (FCT/ UNESP), in collective cages (polyethylene), at a controlled temperature $\left(22 \pm 2{ }^{\circ} \mathrm{C}\right)$, humidity $(50 \pm 10 \%)$ and 12-hour light/ dark cycle with access to food (standard laboratory chow) and water ad libitum.

All procedures were approved by the ethics committee for animal use from FCT/UNESP, Presidente Prudente (SP, Brazil) campus, protocol no. 01/2013.

Experimental groups. The animals were randomly divided into three groups: Control (C); Lesion two days (L2) and

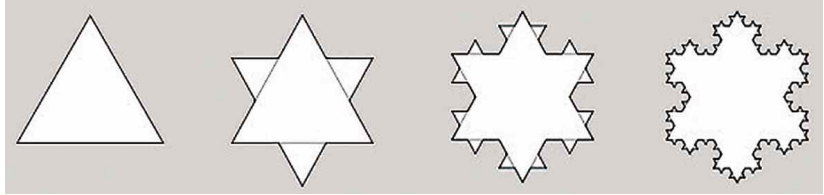

Fig. 1. Koch snowflake.

Lesion seven days (L7). The animals in group C remained in the bioterium and were euthanized paired with the L7 group. Muscle damage was induced in the L2 and L7 groups, following which the animals were kept in the bioterium for two and seven days respectively.

Equipment for inducing stretch injury. Muscle injury was induced using noninvasive mechanical stretching equipment, developed and built at the Laboratory of Bioengineering of the Faculty of Medicine, Ribeirão Preto (São Paulo - Brazil). The equipment was linked to a tetanized electrical current stimulator with an electrical frequency of $25 \mathrm{~Hz}$ (Pachioni et al., 2009).

Protocol of Muscle Injury. The animals were anesthetized through intraperitoneal administration of a combination of Ketamine $(70 \mathrm{mg} / \mathrm{kg}$ ) and Xylazine $(15 \mathrm{mg} / \mathrm{kg})$ (Ozaki et al., 2014). After confirmation of anesthesia, two percutaneous electrodes were introduced into the right hind limb of the animals, the first one in the popliteal fossa and the second in the region of the calcaneous tendon, corresponding to the regions of insertions of the gastrocnemius muscle. Subsequently the animals were placed in the supine position on the equipment to induce stretch injury, with the hip in slight flexion, knee extension, ankle in plantar flexion, and the right hind limb fixed to the equipment with tape (masking tape) by the paw (Fig. 2). The electrical stimulation was performed at sufficient intensity for a complete hind limb contraction, inducing a plantar flexion of the ankle, at which point the trigger of the equipment was pulled, which promoted the movement of abrupt dorsiflexion. The electric current was ceased immediately afterwards. The action of the equipment promoted a blunt movement opposed to the movement

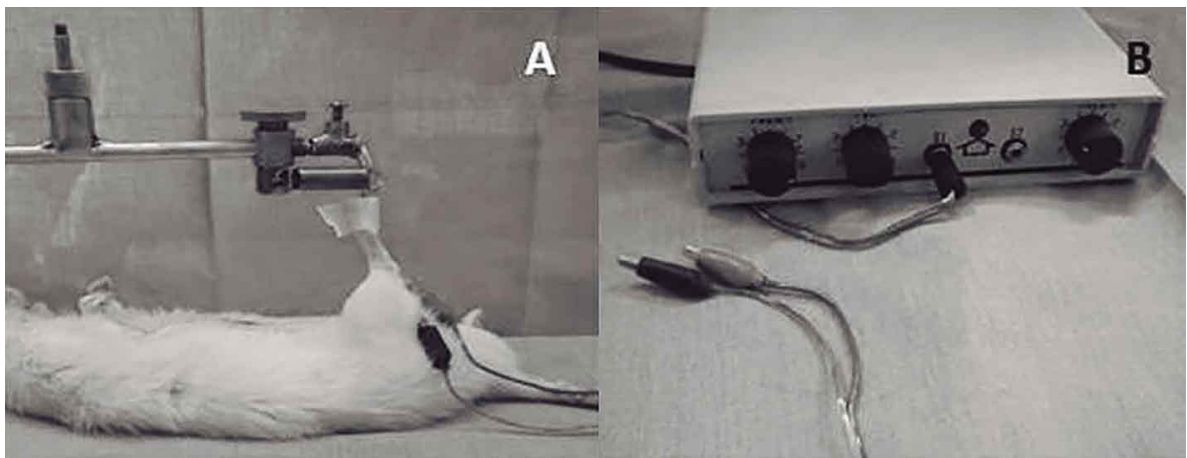

Fig. 2. Equipment to induce stretch injury demonstrating the animal placement (A). The electrical stimulator used to stimulate muscle contraction (B). 
generated by muscle contraction, demanding an eccentric muscle contraction, resulting in a stretch injury. This procedure was repeated 10 times, with a 30 second interval between each series. In each series, $2.25 \mathrm{~J}$ of energy were released, totaling $22.5 \mathrm{~J}$ of energy applied in the injury. This protocol was adapted from Pachioni et al.

Acquisition of tissue samples. After the experimental period the animals were euthanized with an overdose of the anesthetics Ketamine and Xylazine. Subsequently the right gastrocnemius muscles of the animals were collected and immersed in n-hexane cooled in liquid nitrogen, using the freezing method for non-fixed tissues, and stored at $-80{ }^{\circ} \mathrm{C}$ in an ultra-freezer, Coldlab CL580-80V (Camargo Filho et al.; Castoldi et al., 2013). Following this the samples were sectioned in a cryostat, Microm, HM $505 \mathrm{E}$, at $20^{\circ} \mathrm{C}$ with a thickness of $5 \mu \mathrm{m}$ for making the histological slides, which were stained using the hematoxylin and eosin (HE) and picrosirius methods. Histological sections were performed at the lesion site, prior to the preparation of the slides the sections to be cut were analyzed using toluidine blue stain to verify the area of the injury.

Analysis of the Histological Slides. To acquire the images of the slides stained with HE, a Nikon 50i optical microscope was used, linked to an Infinity 1 camera. The images were obtained using NIS-Elements D3 software and performed with a 10x objective lens.

The picrosirius stained slides were photographed using a Leica DM 4000B polarized light microscope, linked to a Leica DFC500 camera, belonging to the Faculty of Dentistry, UNESP, Aracatuba - SP, Brazil. The images were obtained with a 10x objective lens.

For the fractal analysis of the images, the HE and picrosirius stained images were submitted to a binarization process, turning them black and white. At this point the HE images presented the nucleus of the cells as white and the rest of the cell as black. To enable the performance of fractal analysis, an inversion of colors was applied, so that the nucleus became black and the rest of the cell white (Fig. 3). This procedure was necessary because fractal analysis measures the black area of the image. By means of this method we evaluated the inflammatory infiltrate from the inflammatory process triggered by muscle injury. The images of collagen (picrosirius), when observed using a polarized microscope, showed the collagen fibers in red, green, yellow, and the rest of the cell as black. After the binarization process all collagen areas became black and the rest of the cell white (Fig. 4). In this case the analysis was performed on the entire area of collagen, as the colors that differentiated the types of collagen had all been turned black.

Subsequently the analysis of FD was performed using the box-counting method. All procedures, including the preparation process, were performed using Image J software, with the addition of a plug-in named Fractal Dimension and Lacunarit, both available for free on the internet (http:// rsbweb.nih.gov/ij/). The sizes of the boxes used in the analysis were the default sizes of the software $(2,3,4,6,8$, 12, 16, 32 and 64).

Statistical Analysis. The data were tested for normality using the Shapiro-Wilk test. As normal distribution was demonstrated, ANOVA one-way was used with the Tukey post-test to verify the differences between the groups. For all analyzes the significance level was set at $5 \%$.

\section{RESULTS}

The image of HE stained after the binarization process showed the cellular nucleus in black and the rest of the cell, the cytoplasm, plasma membrane, and other elements in white (Fig. 3).

The images of the picrosirius slides were obtained by means of a polarized light microscope and after the binarization process the collagen turned black and the rest of the cell white (Fig. 4).
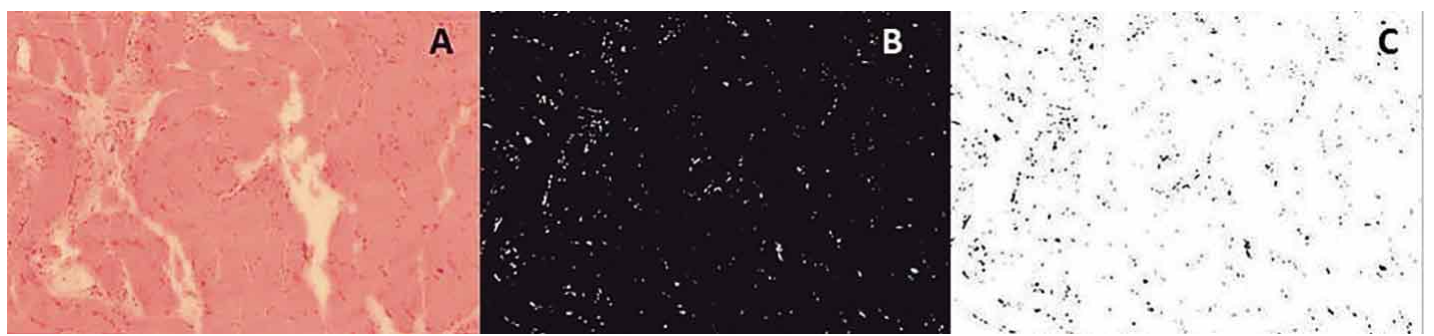

Fig. 3. Picture of the muscle of an animal from the L7 group stained with HE, demonstrating step-by-step how the image was processed to allow analysis of the fractal dimension. A) Original picture. 100x Magnification, HE stained; B) The same image after the binarization process; C) Inverting colors, nucleus in black and the rest of cell white, image ready for fractal analysis. 

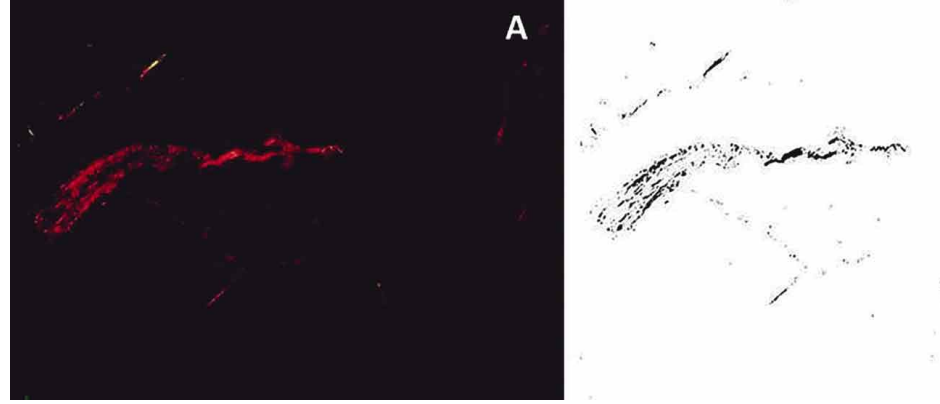

Fig. 4. Image of a muscle of an animal from the L7 group stained with picrosirius. Collagen originally in red, reverted to black to perform the measurement of fractal dimension. A) Original image, 100x magnification, picrosirius stained. B) Result of binarization, collagen area turned black and the rest of the cell white, image ready for fractal analysis.

B

\section{DISCUSSION}

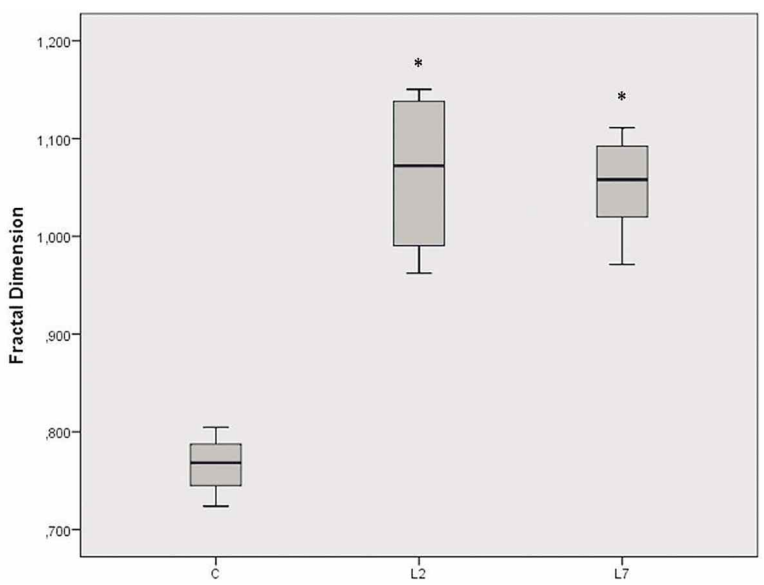

Fig. 5. Box-plot with values of the fractal dimension of slides stained with HE. * Statistical difference compared to group C $(\mathrm{p}=0.000)$.

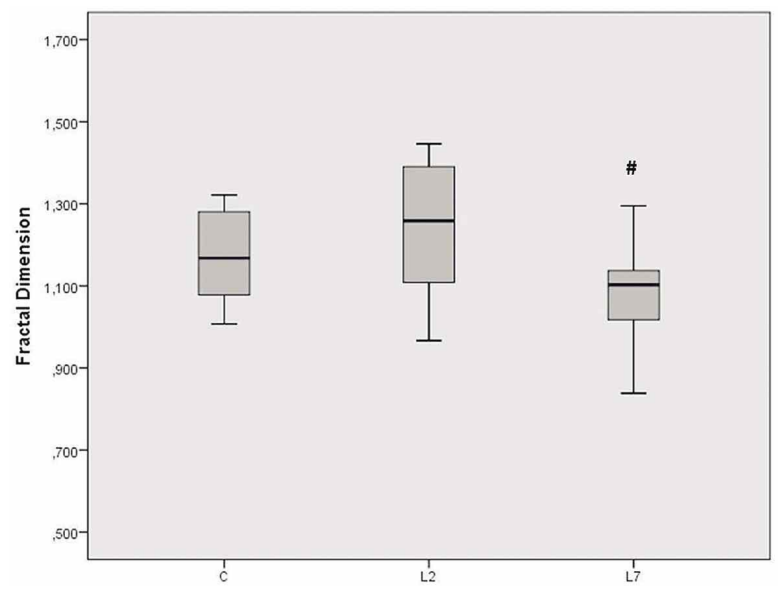

Fig. 6. Values of means and standard deviation of FD of slides stained with picrosirius. \# Statistical difference compared to L2 $(\mathrm{p}=0.001)$. microscope.
The FD analysis of the section stained with $\mathrm{HE}$ showed a significant increase in FD in the L2 and L7 groups compared to the C group ( $\mathrm{p}=0.000)$ (Fig. 5). However there was no significant difference between the experimental groups, L2 and L7.

In the collagen analysis, conducted by means of images stained with picrosirius, the L7 group showed significantly lower values of FD compared to the L2 ( $\mathrm{p}=0.001)$. However there was no significant difference between the L2 and C, or the C and L7 groups (Fig. 6).

The present study demonstrated by means of fractal analysis that the muscle injury caused increased fractal dimension at the lesion site, and such changes had not reverted by the period of seven days post-injury. When analyzing the amount of collagen, it had not changed two days after injury, however after the period of seven days the amount of collagen was significantly lower.

Fractal analysis was used in this research to evaluate the inflammatory process by measuring the size of the inflammatory infiltrate at the site of the injury. The inflammatory infiltrate is identified as a cellular infiltrate diffusely distributed among the muscle cells, due to the influx of lymphocytes to the site of injury (Camargo Filho et al.). When submitted to the binarization process, slides stained with HE demonstrated the nucleus detached from the rest of the cells, allowing measurement of the size of the infiltrate by analyzing the fractal dimension.

Currently histological analysis of muscle tissue is performed qualitatively, through tissue characteristics of the cell morphology; size, nucleus position and presence of inflammatory infiltrate, among others (Camargo Filho et al.). However, this type of analysis is dependent on the analyzer and may present differences among evaluators. In this context, analysis by means of fractal dimension in addition to quantifying the histological changes has the advantage of being independent of the evaluator, since it is an automatic analysis performed by software (Moreira et al.).

The accumulation of cells observed in this study in the first three days after muscle injury, has also been found by other authors, for injuries induced by contusion (Luo et al.), cryoinjury (Alves et al.), crushing (Shono et al., 2013) or stretching (Song et al., 2004), being analyzed by means of slides of muscle tissue stained with HE and evaluated qualitatively under an optical 
Muscle injury triggers the inflammatory process that can be divided into three phases: damage, repair and remodeling. The first phase begins at the time of the injury, when a large number of immune cells accumulate, mainly neutrophils and macrophages, which act in the degradation of damaged structures, however they release cytotoxins into the extracellular space, which also damage healthy cells, exacerbating the inflammatory process (Souza \& Gottfried, 2013)

Seven days after injury a high value of fractal dimension was still observed, when comparing the L7 group with the C group. Other studies with HE slides have also reported larger numbers of nucleated cells seven days after muscle injury (Luo et al.; Myburgh et al., 2012; Shu et al., 2012). During this period the inflammatory process continues its action, now at the stage of repair. The accumulation of nucleated cells remains noticeable at the injury site; although in this period satellite cells are attracted to the site of injury by cytokines released by the macrophages. These cells are stem cells that differentiate into myoblasts and myofibrils in accordance with the growth factor present at the site of injury, promoting myogenesis (Järvinen et al., 2013; Souza $\&$ Gottfried). The formation of new fiber is initiated, but the maturation of these cells and the complete recovery of the injured muscle usually occurs between 14 and 21 days after injury, depending on the severity of the injury.

In this study the collagen (picrosirius) demonstrated changes only in the L7 group compared with the L2 group, with a smaller value of fractal dimension in the L7 group. Studies using the technique of staining with picrosirius when analyzed by polarized light microscope, analyze collagen using birefringence, wherein the collagen type I is evident in color from yellow to red, while type III collagen fibers are shown as greenish and the remainder of the cell is presented as black (Franca et al., 2013; Junqueira et al., 1982; Rodrigues et al., 2014).

The fractal analysis of collagen is able to measure not only the areas in red, corresponding to collagen types I and II, but also others which are in yellow and green, such as collagen type III. This technique proved to be sensitive to changes in the present study, as there were differences among the groups.

Studies conducted to analyze collagen by immune labeling for demonstrating collagen types I and III in muscle injury, found a greater quantity of type I collagen at 7 and 14 days after injury, when compared to the uninjured group. However type III collagen was reduced after seven days compared to the control group, and then increased up to 14 days after injury (de Souza et al.). As the present study did not differentiate between types of collagen, the collagen could have been reduced in the L7 group due to the reduction of type III collagen, which was not compensated for by the increase of collagen type I. Collagen is an important component of skeletal muscle, it is responsible for structure, organizing the muscle tissue at various levels, from the fascia and epimysium to the perimysium and endomysium, being mainly composed of collagen type I and III (Calvi et al., 2012)
This study aimed to demonstrate a new technique for analyzing muscle injury in histological slides; however, some limitations should be noted: the injury protocol, despite having the advantage of not being invasive, allowed for a small variation in the extent of injury, due to differences between animals, such as the length of the hind limb; fractal analysis of collagen using the picrosirius method is not able to differentiate between the types of collagens by showing different colors on histological slides, because after the binarization process all the different colors of collagen had become black.

The results of this study demonstrated that fractal analysis was able to identify and quantify changes in injured skeletal muscle tissue by means of analysis of slides stained with $\mathrm{HE}$ and changes in the collagen in slides stained with picrosirius. This technique could aid the evaluation of histological findings in skeletal muscle tissue, both for scientific research and clinical practice, enabling a standardized measurement of the findings, and a quantitative evaluation of tissue changes.

ACKNOWLEDGMENTS. The authors are grateful to the Brazilian Agency of Resources for Higher Education Personnel (CAPES) for supporting the development of this study.

OZAKI, G.; CAMARGO, R. C. T.; KOIKE, T. E.; GARCIA, T. A.; CASTOLDI, R. C. \& CAMARGO FILHO, J. C. S. Análisis fractal de tejido muscular esquelético en ratas sometidas a lesión por estiramiento. Int. J. Morphol., 33(3):908-913, 2015.

RESUMEN: El objetivo de la investigación fue observar las modificaciones en tejido muscular esquelético en ratas después de la lesión por estiramiento muscular con análisis fractal. En el estudio se incluyeron 19 ratas, divididas en tres grupos, Control $(n=5)(C)$, lesión dos días ( $(n=7)(L 2)$ y lesión siete días (L7). Los cortes histológicos del músculo gastrocnemio fueron coloreados con hematoxilina-eosina para el análisis de la inflamación y picrosirius para la determinación del colágeno. Los cortes histológicos fueron posteriormente analizados por medio de dimensión fractal (FD). Los resultados mostraron valores elevados de FD en proceso inflamatorio en los grupos experimentales L2 y L7, en comparación con grupo C ( $\mathrm{p}=0,000)$. El análisis de colágeno mostró mayor FD en grupo L2 comparado con L7 ( $\mathrm{p}=$ 0,0001 ), se observó diferencia estadísticamente significativa con los demás. En resumen, esta investigación ha demostrado que el análisis fractal fue capaz de identificar las alteraciones del proceso inflamatorio en tejido muscular esquelético después de la lesión.

PALABRAS CLAVE: Análisis fractal; Lesión en músculo esquelético; Colágeno; Patología.

\section{REFERENCES}

Alves, A. N.; Fernandes, K. P. S.; Melo, C. A. V.; Yamaguchi, R. Y.; França, C. M.; Teixeira, D. F.; Bussadori, S. K.; Nunes, F. D. \& Mesquita-Ferrari, R. A. Modulating effect of low level-laser therapy on fibrosis in the repair process of the tibialis anterior muscle in rats. Lasers Med. Sci., 29(2):813$21,2014$. 
Calvi, E. N. C.; Nahas, F. X.; Barbosa, M. V.; Calil, J. A.; Ihara, S. S. M.; Silva, M. S.; Franco, M. F. \& Ferreira, L. M. An experimental model for the study of collagen fibers in skeletal muscle. Acta Cir. Bras., 27(10):681$6,2012$.

Camargo Filho, J. C. S.; Garcia, B. C.; Kodama, F. Y.; Bonfim, M. R.; Vanderlei, L. C. M.; Ramos, E. M. C.; Camargo, R. C. T.; Padulla, S. A. T. \& Maeda, J. K. Effects of aerobic exercise on the skeletal muscle of rats exposed to cigarette smoke. Rev. Bras. Med. Esporte, 17(6):416-9, 2011.

Castoldi, R. C.; Camargo, R. C. T.; Magalhães, A. J. B.; Ozaki, G. A. T.; Kodama, F. Y.; Oikawa, S. M.; Papoti, M. \& Camargo Filho, J. C. S. Concurrent training effect on muscle fibers in Wistar rats. Motriz. Rev. Educ. Fis., 19(4):717-23, 2013.

de Souza, T. O.; Mesquita, D. A.; Ferrari, R. A.; Dos Santos Pinto, D. Jr.; Correa, L.; Bussadori, S. K.; Fernandes, K. P. \& Martins, M. D. Phototherapy with low-level laser affects the remodeling of types I and III collagen in skeletal muscle repair. Lasers Med. Sci., 26(6):803-14, 2011.

Franca, C. M.; de Loura Santana, C.; Takahashi, C. B.; Alves, A. N.; De Souza Mernick, A. P.; Fernandes, K. P.; de Fátima Teixeira da Silva, D.; Bussadori, S. K. \& Mesquita-Ferrari, R. A. Effect of laser therapy on skeletal muscle repair process in diabetic rats. Lasers Med. Sci., 28(5):1331-8., 2013

Gupta, S.; Hartley, R.; Khan, U. T.; Singapuri, A.; Hargadon, B.; Monteiro, W.; Pavord, I. D.; Sousa, A. R.; Marshall, R. P.; Subramanian, D.; Parr, D.; Entwisle, J. J.; Siddiqui, S.; Raj, V. \& Brightling, C. E. Quantitative computed tomography-derived clusters: redefining airway remodeling in asthmatic patients. J. Allergy Clin. Immunol., 133(3):729-38.e18, 2014.

Järvinen, T. A.; Järvinen, M. \& Kalimo, H. Regeneration of injured skeletal muscle after the injury. Muscles Ligaments Tendons J., 3(4):337-45, 2014.

Junqueira, L. C.; Montes, G. S. \& Sanchez, E. M. The influence of tissue section thickness on the study of collagen by the Picrosirius-polarization method. Histochemistry, 74(1):153-6, 1982.

Karperien, A.; Jelinek, H. F.; Leandro, J. J.; Soares, J. V.; Cesar, R. M. Jr. \& Luckie, A. Automated detection of proliferative retinopathy in clinical practice. Clin. Ophthalmol., 2(1):109-22, 2008.

Lee, L. H.; Tambasco, M.; Otsuka, S.; Wright, A.; Klimowicz, A.; Petrillo, S.; Morris, D.; Magliocco, A. \& Bebb, D. G. Digital differentiation of nonsmall cell carcinomas of the lung by the fractal dimension of their epithelial architecture. Micron, 67:125-31, 2014

Luo, L.; Sun, Z.; Zhang, L.; Li, X.; Dong, Y. \& Liu, T. C. Effects of low-level laser therapy on ROS homeostasis and expression of IGF-1 and TGF-b1 in skeletal muscle during the repair process. Lasers Med.Sci., 28(3):72534, 2013.

Mendonca, M. B. M.; Garcia, C. A. A.; Nogueira, R. A.; Gomes, M. A. F.; Valença, M. M. \& Oréfice, F. Análise fractal da vasculatura retínica: métodos de segmentação e de cálculo dimensional. Arq. Bras. Oftalmol., 70(3):413-22, 2007.

Michallek, F. \& Dewey, M. Fractal analysis in radiological and nuclear medicine perfusion imaging: a systematic review. Eur. Radiol., 24(1):60-9, 2014.

Moreira, R. D.; Moriel, A. R.; Murta Junior, L. O.; Neves, L. A. \& Godoy, M. F. Dimensão fractal na quantificação do grau de rejeição celular miocárdica pós-transplante cardíaco. Rev. Bras. Cir. Cardiovasc., 26(2):155-63, 2011.
Myburgh, K. H.; Kruger, M. J. \& Smith, C. Accelerated skeletal muscle recovery after in vivo polyphenol administration. J. Nutr. Biochem., 23(9):1072-9, 2012.

Ozaki, G. A. T.; Koike, T. E.; Castoldi, R. C.; Garçon, A. A. B.; Kodama, F. Y.; Watanabe, A. Y.; Job, A. E.; Louzada, M. J. Q.; Camargo, R. C. T. \& Camargo Filho, J. C. S. Efeitos da remobilização por meio de exercício físico sobre a densidade óssea de ratos adultos e idosos. Motricidade, 10(3):71-8, 2014

Pachioni, C. A. S.; Mazzer, N.; Barbieri, C. H.; de Camargo, M. R.; Fregonesi, C. E. P. T.; do Carmo, E. M.; Nozabielli, A. J. L. \& Martinelli, A. R. Stretch Injuries of Skeletal Muscles: Experimental Study in Rats' Soleus Muscle. Int. J. Morphol., 27(4):1139-46, 2009.

Park, S. H.; Shin, J. W.; Kang, Y. G.; Hyun, J. S.; Oh, M. J.; Shin, J. W. Texture analyses show synergetic effects of biomechanical and biochemical stimulation on mesenchymal stem cell differentiation into early phase osteoblasts. Microsc. Microanal., 20(1):219-27, 2014.

Ristanovic, D.; Stefanovic, B. D. \& Puskas, N. Fractal analysis of dendrite morphology using modified box-counting method. Neurosci. Res., 84:64$7,2014$.

Rodrigues, N. C.; Brunelli, R.; Abreu, D. C.; Fernandes, K.; Parizotto, N. A. \& Renno, A. C. Morphological aspects and Cox-2 expression after exposure to 780 -nm laser therapy in injured skeletal muscle: an in vivo study. Braz. J. Phys. Ther, 0:0, 2014.

Shono, J.; Sakaguchi, S.; Suzuki, T.; Do, M. K.; Mizunoya, W.; Nakamura, M.; Sato, Y.; Furuse, M.; Yamada, K.; Ikeuchi, Y. \& Tatsumi, R. Preliminarytime-course study of antiinflammatory macrophage infiltration in crush-injured skeletal muscle. Anim. Sci. J., 84(11):744-50, 2013.

Shu, B.; Yang, Z.; Li, X. \& Zhang, L. Q. Effect of different intensity pulsed ultrasound on the restoration of rat skeletal muscle contusion. Cell Biochem. Biophys., 62(2):329-36, 2012.

Song, H.; Nakazato, K. \& Nakajima, H. Effect of increased excursion of the ankle on the severity of acute eccentric contraction-induced strain injury in the gastrocnemius: an in vivo rat study. Am. J. Sports Med., 32(5):1263$9,2004$.

Souza, J. d. \& Gottfried, C. Muscle injury: review of experimental models. $J$. Electromyogr. Kinesiol., 23(6):1253-60, 2013.

\section{Correspondence to:}

Guilherme Akio Tamura Ozaki

Universidade Estadual Paulista Júlio de Mesquita Filho

Faculdade de Ciências e Tecnologia de Presidente Prudente

Roberto Simonsen, 305

Cidade Universitária, 19060900

Presidente Prudente, SP

BRAZIL

\section{Email: guiozaki@hotmail.com}

